\title{
AC 2007-2928: INTEGRATING THE HOBBY SHOP, A NON-CONVENTIONAL FRESHMEN LAB, INTO THE ELECTRICAL ENGINEERING CURRICULUM
}

Hassan El-Kishky, The University of Texas-Tyler

Ralph Hippenstiel, The University of Texas-Tyler 


\title{
Integrating the Hobby Shop, a Non-conventional Freshmen Lab, into the Electrical Engineering Curriculum
}

\begin{abstract}
This paper presents interim results of a project aimed at increasing the enrollment and retention of engineering students through the development and integration of a broad-based hands-on, design and development lab, the Hobby Shop, into the introductory electrical engineering course at the University of Texas, Tyler. The introductory course in our electrical engineering (EE) program was redesigned based on the Hobby Shop as the core component. A library of projects, circuits, and systems was compiled and added to the course material and made accessible to the students enrolled in the course. Moreover, a set of practical hands-on workshops such as hands-on soldering workshops were developed and added to the course contents. Feedback from students who went through the first Hobby Shop based introductory EE course was collected and analyzed. Furthermore, the use of the Hobby Shop as a tool to boost recruitment effort is also discussed in the paper.
\end{abstract}

\section{Introduction}

Declining enrollment figures and poor retention rates are signs of a distorted picture of engineering education. The retention of engineering students is a very difficult problem [1]. Demanding engineering curricula and ill-prepared students are often cited for poor retention and graduation among engineering students. The problem is even more significant amongst underrepresented minority groups. Lack of proper academic mindset and attitude for success and very limited computer skills were cited as main challenges for incoming engineering students [2]. Also, lack of experience in bringing an engineering design concept to a working prototype and poor written oral communication skills significantly contribute to the retention problem [2].

The Electrical Engineering (EE) Department of the University of Texas at Tyler (UT-Tyler) is part of the College of Engineering and Computer Science and has been in existence for 9 years. Our first graduating class was in May 1999, consisting of students who completed their preengineering coursework at the area junior colleges. The first graduating class to include students that completed all four years at UT-Tyler was in the year 2003. The EE program was granted accreditation by the Accreditation Board for Engineering and Technology (ABET) in the fall of 2002 which was a milestone in the development of our program. In an attempt to boost the enrollment university-wide, UT Tyler created the position of the Dean of Enrollment that has a variety of active recruitment programs under his office. In a continued effort to increase freshmen retention rates, the university added the "Freshman Experience", a non-credit course that is designed to help make a smooth transition from high school to college environment. Other steps to increase retention were taken by the university such as forming freshmen study groups and a variety of counseling services. The success rates of these efforts in retaining and graduating electrical engineering students are however far below the average university-wide. One approach this paper is reporting on to increasing retention rates of incoming freshmen electrical engineering students is to address the student's "perception and expectation of electrical engineering" as well as find ways to match the students "expectations" without compromising the theoretical foundations in the EE curriculum [3]. 


\section{Past and present pictures of the program}

Table 1 shows the enrollment, retention, and graduation rates in the electrical engineering program. Although enrollment figures showed a steady increase in the last three years with an enrollment increase of $275 \%$ between 2002/2003 and 2004/2005, the retention rates after the freshman year are still below 50\% with $42.9 \%$ in 2003/2004. More alarming is the 5-year graduation rate of electrical engineering students which can be described as far below a national average that is slightly over $50 \%$.

Table 1: Enrollment, retention, and graduation in the Electrical Engineering Program

The University of Texas at Tyler

Electrical Engineering Program

\begin{tabular}{|c|c|c|c|c|c|c|c|c|c|c|c|c|c|c|}
\hline & $\begin{array}{c}\text { Freshman } \\
\text { cohort }^{1}\end{array}$ & \multicolumn{6}{|c|}{ Continuation rates } & \multicolumn{7}{|c|}{$\sim \sim ~$ Graduation and continuation rates } \\
\hline & & contins & led to & continu & ued to & contins & led to & gradu & ated & continu & led to & gradu & ated & continued to \\
\hline Cohort year & Headcount & 2nd- & year & $3 r d-y$ & year & 4th- & jear & in 4 & yrs & 5th $y$ & jear & in 5 & yrs & 6th year \\
\hline 1998-1999 & 12 & 3 & $25.0 \%$ & 3 & $25.0 \%$ & 3 & $25.0 \%$ & 2 & $16.7 \%$ & 0 & $0.0 \%$ & 0 & $16.7 \%$ & 0 \\
\hline $1999-2000$ & 6 & 3 & $50.0 \%$ & 3 & $50.0 \%$ & 2 & $33.3 \%$ & 1 & $16.7 \%$ & 1 & $20.0 \%$ & 1 & $33.3 \%$ & 0 \\
\hline $2000-2001$ & 9 & 3 & $33.3 \%$ & 2 & $22.2 \%$ & 2 & $22.2 \%$ & 0 & $0.0 \%$ & 1 & $11.1 \%$ & & & \\
\hline $2001-2002$ & 12 & 2 & $16.7 \%$ & 3 & $25.0 \%$ & 2 & $16.7 \%$ & & & & & & & \\
\hline $2002-2003$ & 8 & 3 & $37.5 \%$ & 4 & $50.0 \%$ & & & & & & & & & \\
\hline 2003-2004 & 14 & 6 & $42.9 \%$ & & & & & & & & & & & \\
\hline 2004-2005 & 22 & & & & & & & & & & & & & \\
\hline
\end{tabular}

${ }^{1}$ Enrolled Summer or Fall, Full-time Degree-Seeking

To assess the effect of the Hobby Shop on retention of electrical engineering students, the investigators relied only on enrollment numbers and statistics obtained from those who enrolled in the integrated EENG 1201-Hobby Shop in the spring of 2006. Recent enrollment data shows that $65 \%$ of the students who enrolled in the integrated EENG 1201-Hobby Shop in spring of 2006 are still in the program in the spring of 2007. This is very encouraging, given low previous retention rates.

\section{The Hobby Shop}

The main objective of this project is to increase retention rates of incoming electrical engineering freshman students. Our approach to increasing retention rates is based on the introduction of a non-conventional design and development lab, the Hobby Shop. Through the Hobby Shop students will be able to work on design and development projects from a pool of projects that are carefully selected by the investigators. Moreover, students will be encouraged to submit their own design and development proposals to the project repository of the Hobby Shop. The Hobby Shop will be the place where freshman students work on the design and prototype realization of circuits and systems they always wanted to build and the place for hands-on experience throughout their freshman year. The Hobby Shop will be an integral part of the freshman year courses, namely, ENGR 1200-Engineering Methods, and EENG 1201-Electrical Engineering I. 
The size and level of sophistication of the Hobby Shop projects are usually determined by the available budget and time. Robotic bugs and vehicles with track and obstacle sensors were the most common choice of students enrolling in the Hobby Shop. Other interesting projects that students chose include an electronic guitar, an iPod dock station, and a color detection machine.

The work in the project started late in the summer of 2005 and the laboratory was fully functional early during the spring of 2006. Several undergraduate lab assistants worked on the task of preparing a categorized set of circuit project plans for the Hobby Shop and compiling them into a library that was eventually made accessible to students late in the fall of 2005. Each project included schematics, a brief description of the use of the circuit, its functionality and application limitations. Also, several short talks were given to freshmen classes across campus with a focus on engineering students in particular. The project was promoted and potential participants were invited to join in and see for themselves the early hands-on design experience in the electrical engineering. Even though the lab was still in the development phase in the fall of 2005, a small number of students enrolling in the introductory engineering course, ENGR 1200 participated in the Hobby Shop and some of them partially built their semester team design projects in the hobby shop.

\section{Integration and assessment of the Hobby Shop}

The investigators worked on the task of integrating the hobby shop into introductory freshmen engineering courses such as ENGR 1200-Engineering Methods and EENG 1201-Electrical Engineering I. The effort was successful in integrating the project into EENG 1201, however, there was not much success in regards to integrating the project into ENGR 1200. The main reason that we couldn't integrate the hobby shop into ENGR 1200 was the shared ownership and coordination of the course between the mechanical engineering (ME) and electrical engineering (EE) departments, where faculty members from both departments share the teaching load of the course with course syllabi, objectives, and outcomes all set to address both ME and EE programs. Nonetheless, we will continue promoting the project among ENGR 1200 students and we hope that the drive for the hobby shop will continue to gain momentum.

Table 2: Courses directly supported by the project

\begin{tabular}{|l|l|l|}
\hline $\begin{array}{l}\text { COURSE } \\
\text { (Placement in curriculum) }\end{array}$ & TITLE & Project Contribution \\
\hline $\begin{array}{l}\text { ENGR 1200 } \\
\text { (Fall - Freshman year) }\end{array}$ & $\begin{array}{l}\text { Engineering Methods } \\
\text { (Required) }\end{array}$ & $\begin{array}{l}\text { Build and test simple electronic circuits and } \\
\text { systems such as power supplies, photo-voltaic } \\
\text { (PV) cells, electromechanical systems. }\end{array}$ \\
\hline $\begin{array}{l}\text { EENG 1201 } \\
\text { (Spring - Freshman year) }\end{array}$ & $\begin{array}{l}\text { Electrical Engineering I } \\
\text { (Required) }\end{array}$ & $\begin{array}{l}\text { Build and test signal conditioning circuits, } \\
\text { power electronics systems, communication } \\
\text { circuits. }\end{array}$ \\
\hline
\end{tabular}


The assessment of the project starts as soon as the installation and setup of the equipment starts. Several metrics were used to assess the achievement of the project goals and objectives. One of the main assessment tools is the calculation of the retention rates. To assess the success rate of the Hobby Shop in providing practical hands-on experience in the design and development to incoming freshmen students, the students were surveyed twice. The first survey was focused on assessing students' perception and attitude towards electrical engineering. The survey was given to the students for the first time at the beginning of their freshman year. The second one-the exit survey was focused in assessing students' satisfaction with the Hobby Shop and the extent to which the Hobby Shop has influenced their perception of Electrical Engineering. The survey was given to the students at the end of the second semester of the freshman year.

At the beginning of spring of 2006, the investigators surveyed the students enrolled in EENG 1201 and 20 out of 22 students showed strong interest in participating in the project. Out of those students, 14 students finished their hobby shop projects with prototypes completed and tested along with a poster presentation describing each project by the end of the spring semester.

Moreover, throughout the spring of 2006, we added several important hands-on activities to the hobby shop that we thought will make the hobby shop more useful to students. Starting in the spring of 2006, the student lab assistants offered several hands-on circuit simulation, building, and soldering workshops for hobby shop participants. The participation in the hands-on workshops was a success and the feedback we received was very good.

Table 3: Exit survey of Hobby Shop participants who went through EENG 1201

\begin{tabular}{|l|}
\hline Q1: Please rate your over all Hobby Shop experience! \\
\hline Q2: How did the Hobby Shop meet your expectations of the freshman year? \\
\hline Q3: How did you like building circuits and projects in the Hobby Shop? \\
\hline Q4: How did you like the open lab (walk-in) setting of the Hobby Shop? \\
\hline Q5: How did you rate the hands-on experience you gained in the Hobby Shop? \\
\hline Q6: Are you planning to continue using the Hobby Shop in future? \\
\hline Q7: Please rate how the Hobby Shop influenced your perception of Electrical Engineering? \\
\hline
\end{tabular}

Table 3 summarizes the main questions in the exit survey given to the students who participated in the Hobby Shop as an integral component the introductory electrical engineering course, EENG 1201-Electrical Engineering I. 


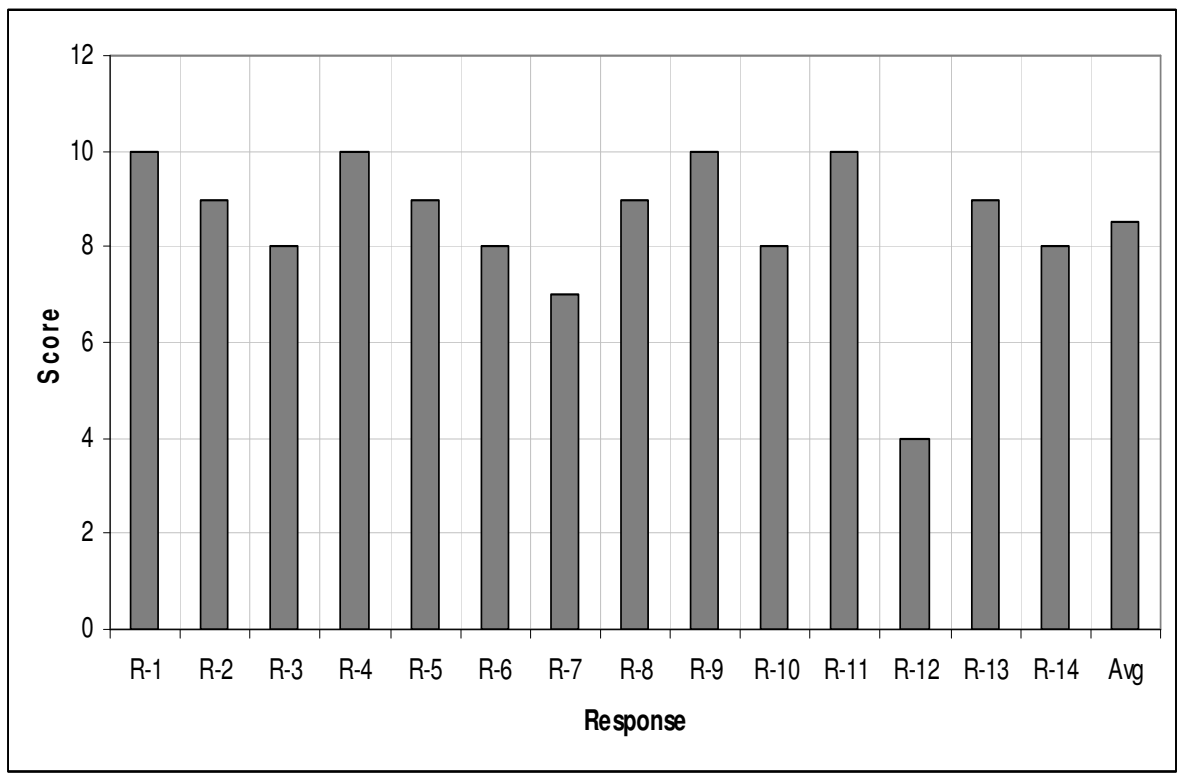

Fig. 1: Response to question 1 in the exit survey

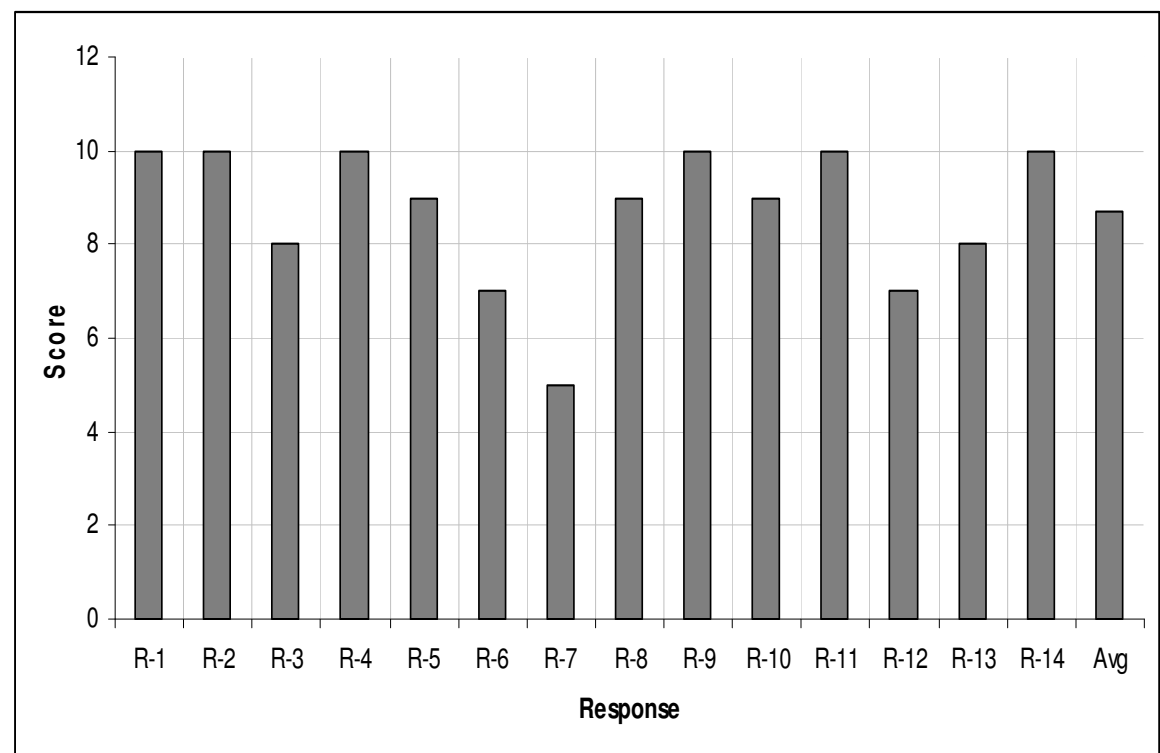

Fig. 2: Response to question 2 in the exit survey

Figures 1 and 2 present the scores of the first two questions of the survey. The second questions in particular addressed the issue of incoming freshmen students expectations of their freshmen year and how relevant was the hobby shop in meeting those expectations. 


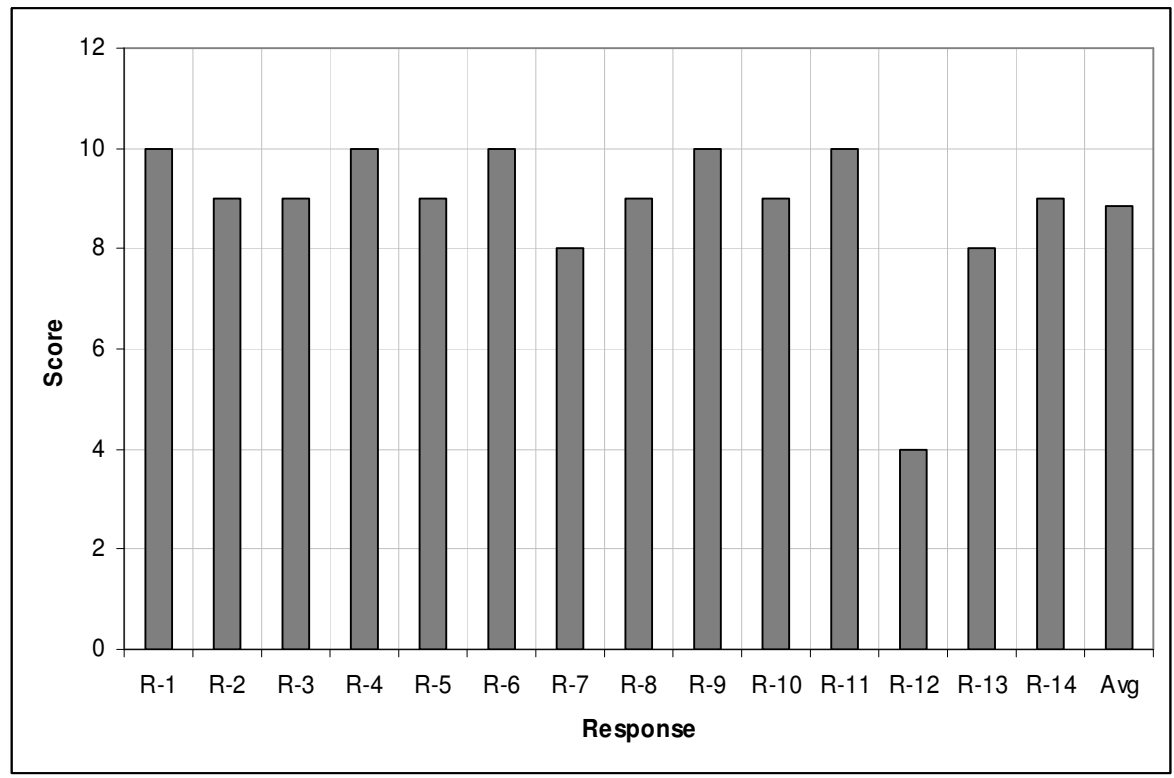

Fig. 3: Response to question 5 in the exit survey

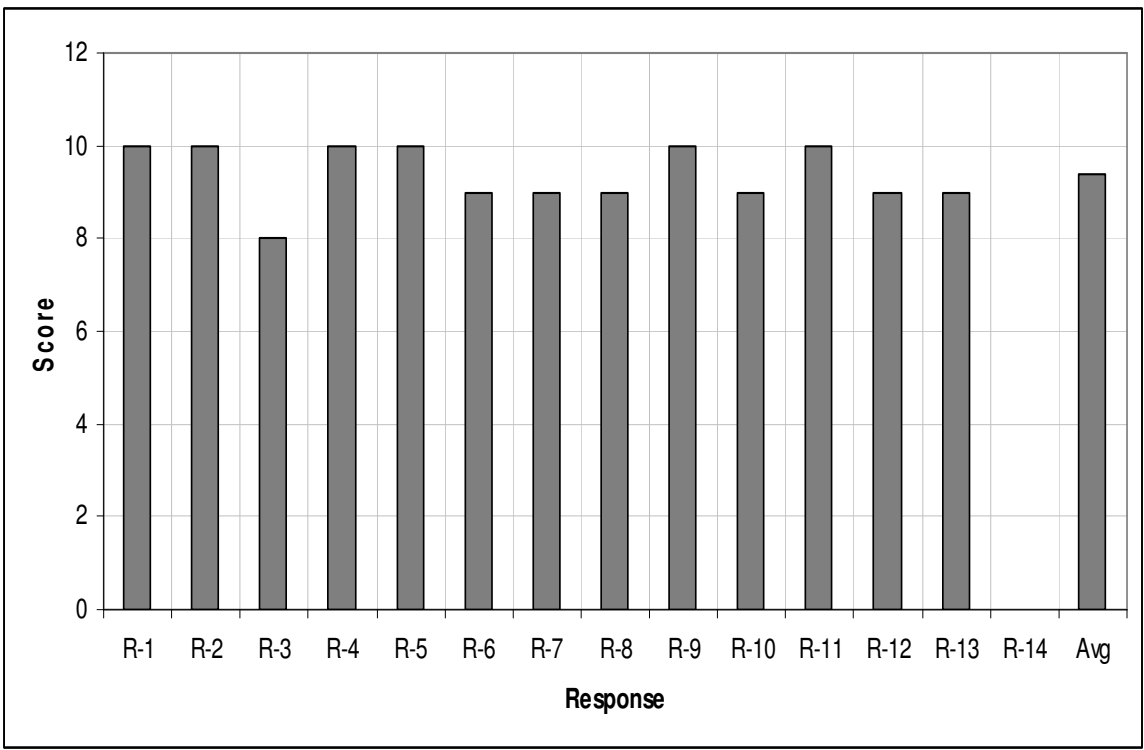

Fig. 4: Response to question 7 in the exit survey

Figures 3 and 4 present the scores of the questions 5 and 7 of the survey. These questions have a significant importance in the assessment of the Hobby Shop as they in particular deal with measuring the amount of hands-on experience gained as well how the Hobby Shop influenced their perception of Electrical Engineering. Figure 5 below presents the average score of the exit survey questions. 


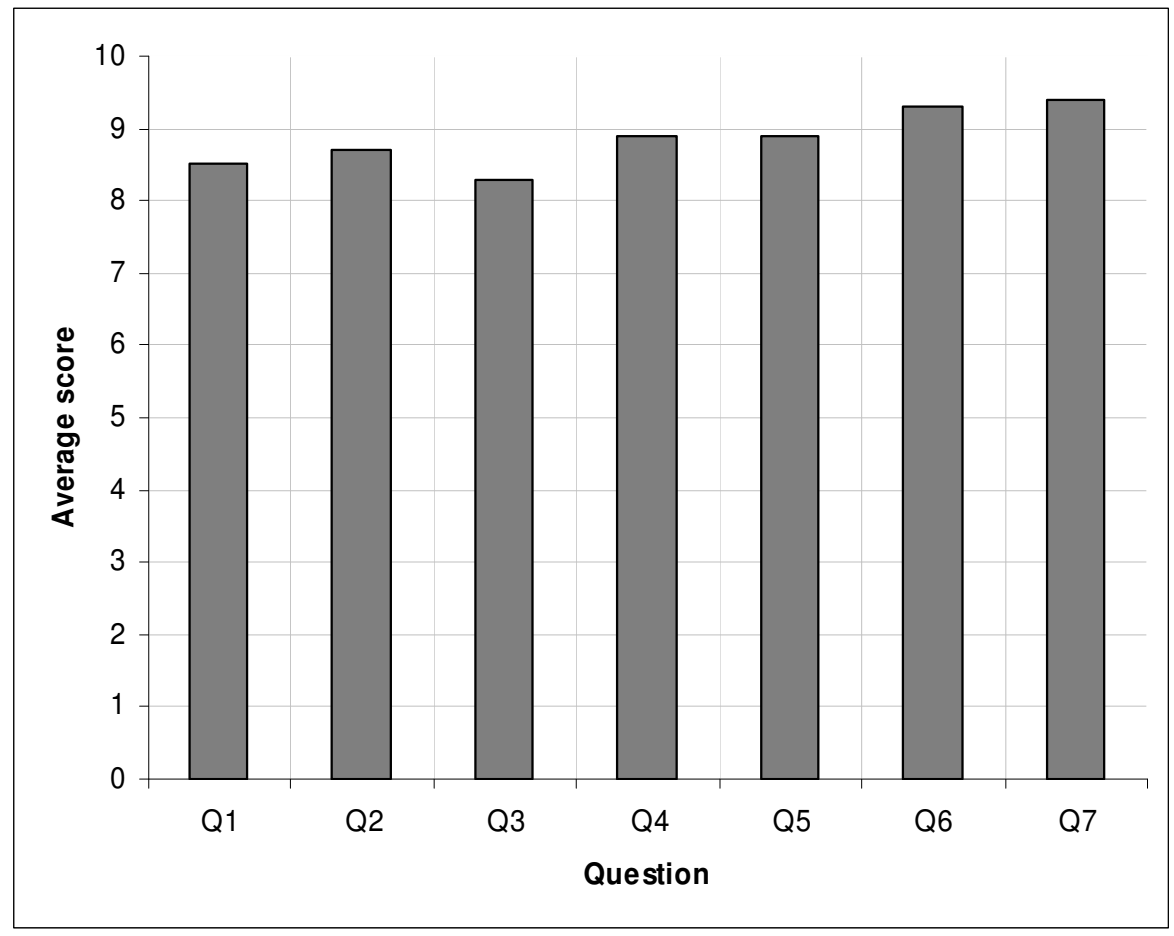

Fig. 5: Average scoring of the Hobby Shop exit survey questions

\section{Recruitment Activities}

The Hobby Shop was the center of show and tell activities of the electrical engineering department during the College of Engineering's Open House event in the spring of 2006. Students and teachers from several high schools in the region visited the Hobby Shop in groups where 5 student projects were displayed and explained to students. Moreover, the Hobby Shop and its mission were explained to the visiting students and their teachers. Furthermore, arrangements are being made to invite several groups of middle school students to spend half a day at the Hobby Shop where simple circuit design and other hands-on activities will take place. The short-term agenda will focus on establishing ties with regional secondary schools where interested students and science clubs' members can participate in some of the relevant Hobby Shop activities in order to boost our overall enrollment figures.

\section{Conclusions}

The Hobby Shop, a non conventional lab designed to provide incoming Electrical Engineering freshmen students with hands-on design and development experience was developed. The lab was integrated into the Electrical Engineering program at the University of Texas, Tyler as a core component of the electrical engineering introductory course EENG 1201. Exit surveys of the Hobby Shop participants showed a significant influence of the Hobby Shop on the students' expectations of their freshmen electrical engineering year. Moreover, the Hobby Shop showed a significant influence on the perception of incoming freshmen students. The project has a positive effect on the amount of hands-on experience and confidence gained by students which in turn my reflect positively on the retention rates. 


\section{References}

1. Anderson-Rowland, Mary, "A first Year Engineering Student Survey to Assist Recruitment and Retention," Proceedings, Frontiers in Education, 1996.

2. Pomalaza-Raez, Carlos, and Groff, Brenda, "Retention 101: Where Robots Go... Students Follow," Journal of Engineering Education, January 2003.

3. El-Kishky, Hassan, and Hippenstiel, Ralph, "Introducing a non-conventional design and development lab, the Hobby Shop to increase retention of Electrical Engineering Students," TETC grant-June 2005. 